\title{
EFFECTS OF MELANOMA DERIVED EXOSOMES ON PERITUMORAL STROMAL CELLS
}

Tünde Buknicz ${ }^{1}$, Barbara Gubán ${ }^{1}$, Beáta S. Bolla ${ }^{1}$, Krisztina Buzás ${ }^{2,3}$,

Mária Harmati ${ }^{2}$, Árpád Bálind ${ }^{2}$, Péter Horváth ${ }^{2}$, Zsuzsanna Bata-Csörgö ${ }^{1}$, Lajos Kemény ${ }^{1,4}$, István Németh ${ }^{1}$

\author{
1 Department of Dermatology and Allergology, University of Szeged, Szeged, Hungary \\ 2 Biological Research Center, Institute of Biochemistry \\ 3Faculty of Dentistry, University of Szeged, Hungary \\ 4 MTA-SZTE Dermatological Research Group, University of Szeged, Szeged, Hungary
}

\section{BACKGROUND AND AIMS}

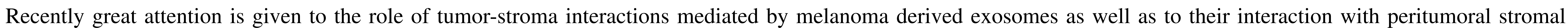

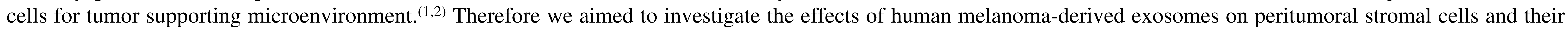
role in spontaneous cell fusion, previously described by our research group.

\section{MATERIALS AND METHODS}

- We used freshly isolated normal human dermal fibroblasts, myofibroblasts and adipose derived mesenchymal stem cells (Ad-MSC) for our experiments.

- Exosomes were obtained with differentialfiltration and ultrafugation.

- To assess proliferation and viability we used xCELLigence system and MTT assay according to the manufacturer's protocol.

- Wound healing model was performed to assess migratory capacity of cells.

- Immunofluorescent staining was performed with monoclonal mouse anti-human smooth muscle actin (SMA) antibody, samples were examined in epifluorescent microscope.

\section{$\underline{\text { RESULTS }}$}

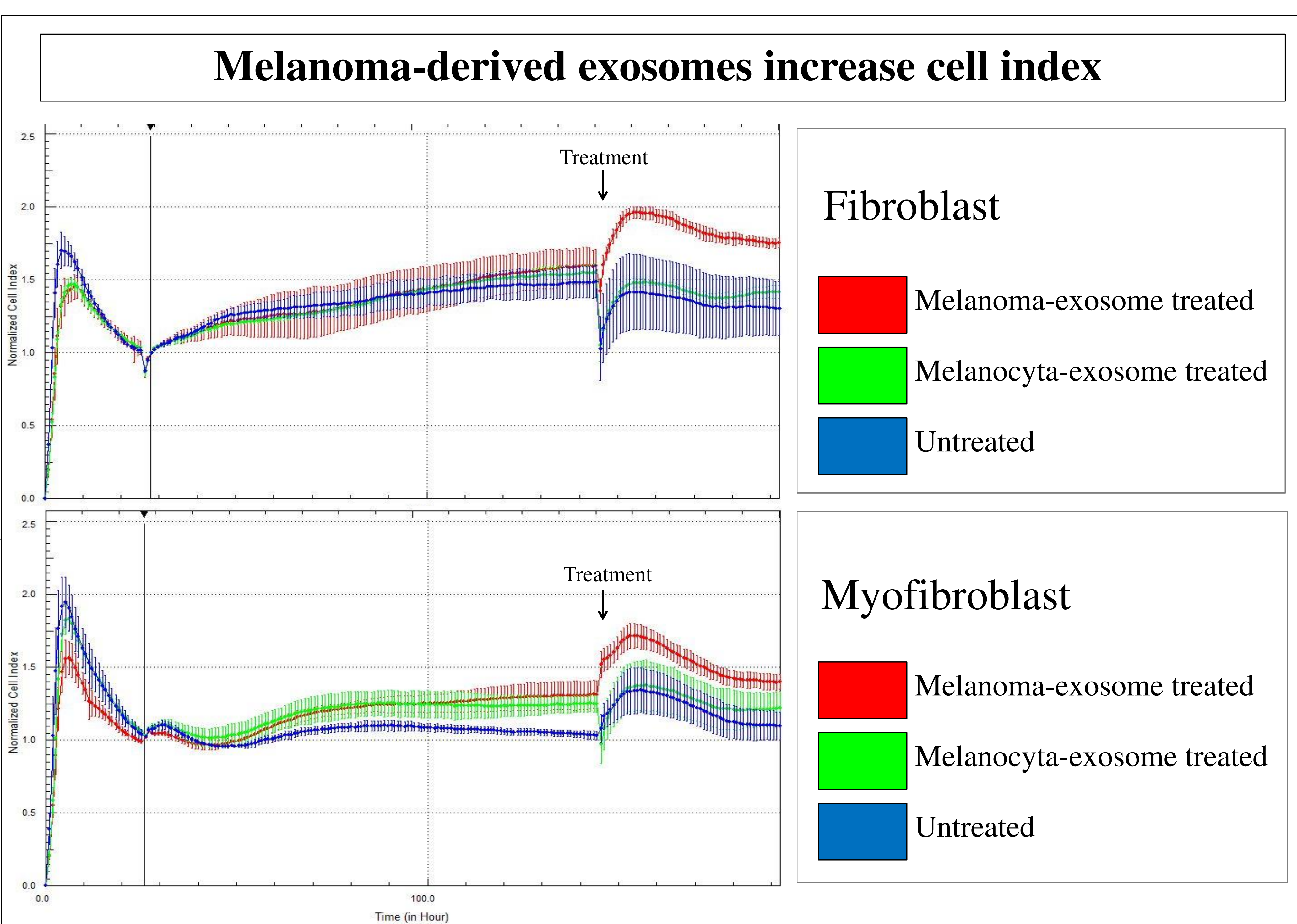

Melanoma-derived exosomes attenuate metabolic activity of cells

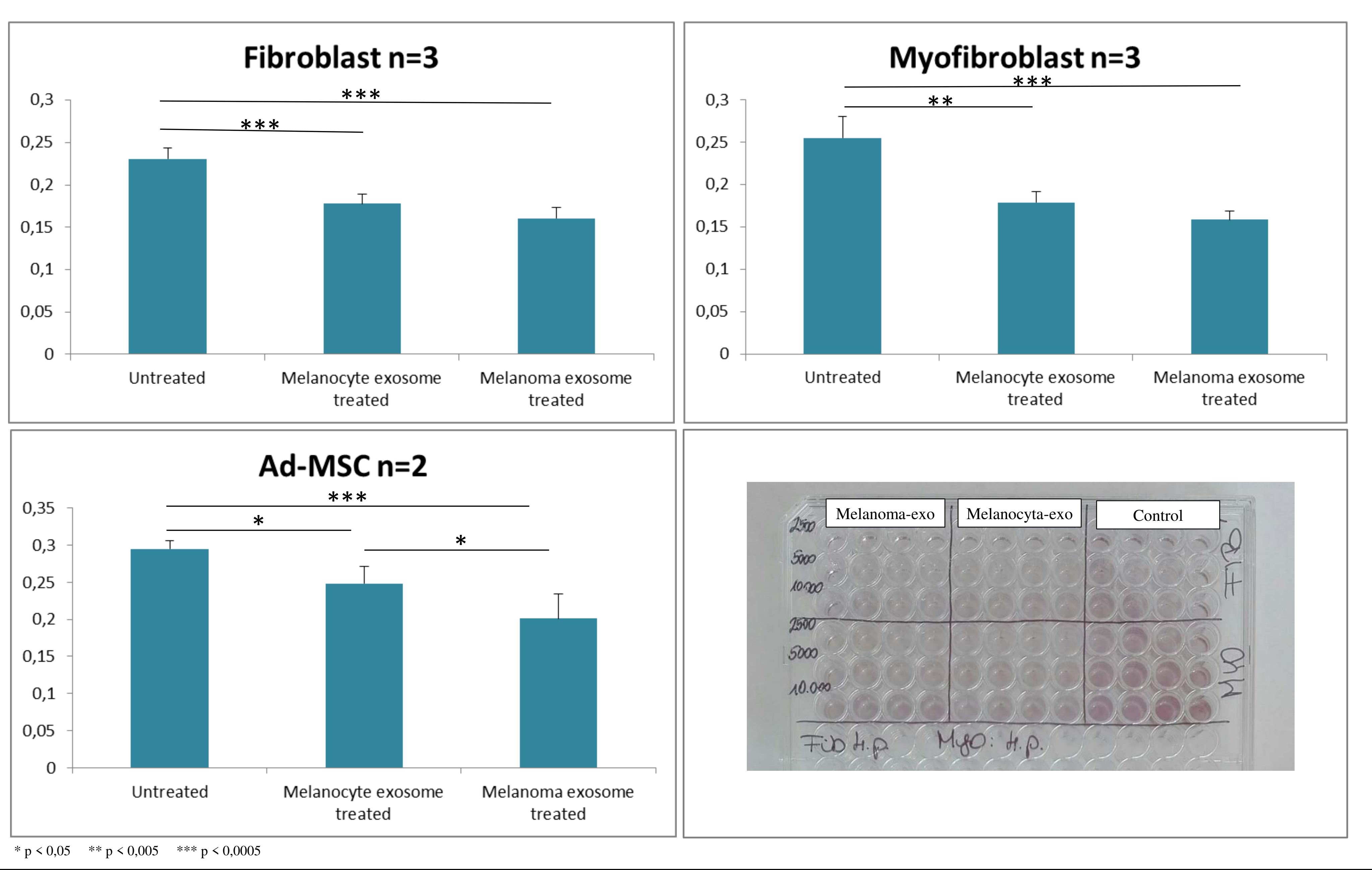

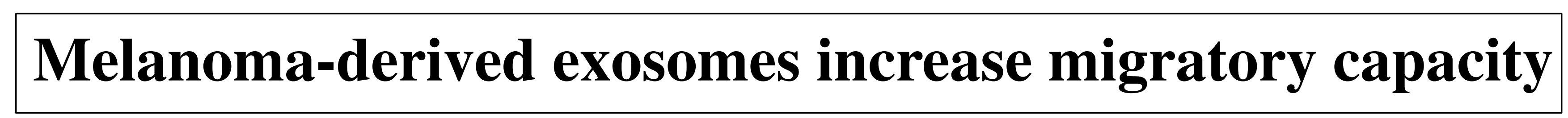
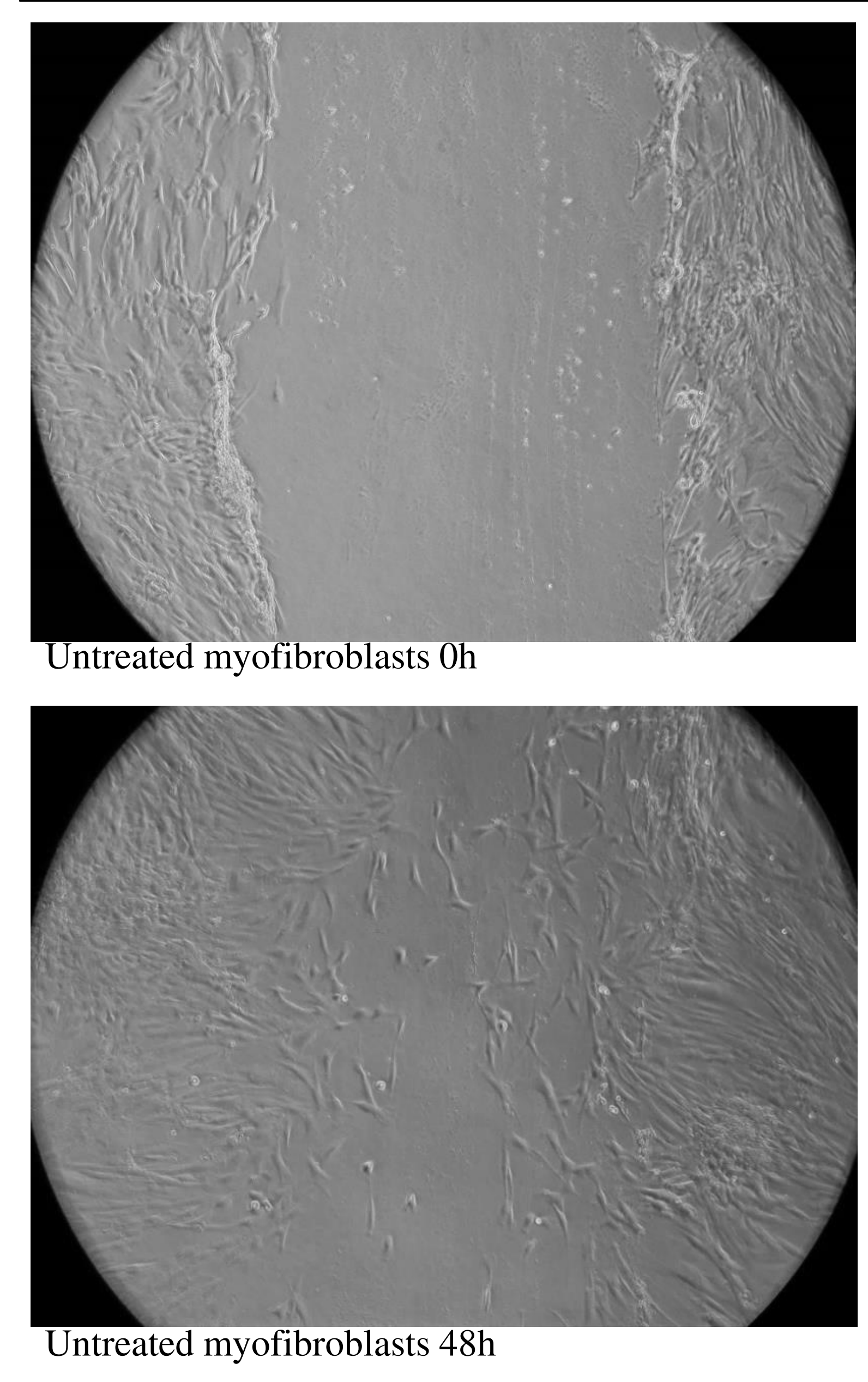

Average speed [micrometer/minute]
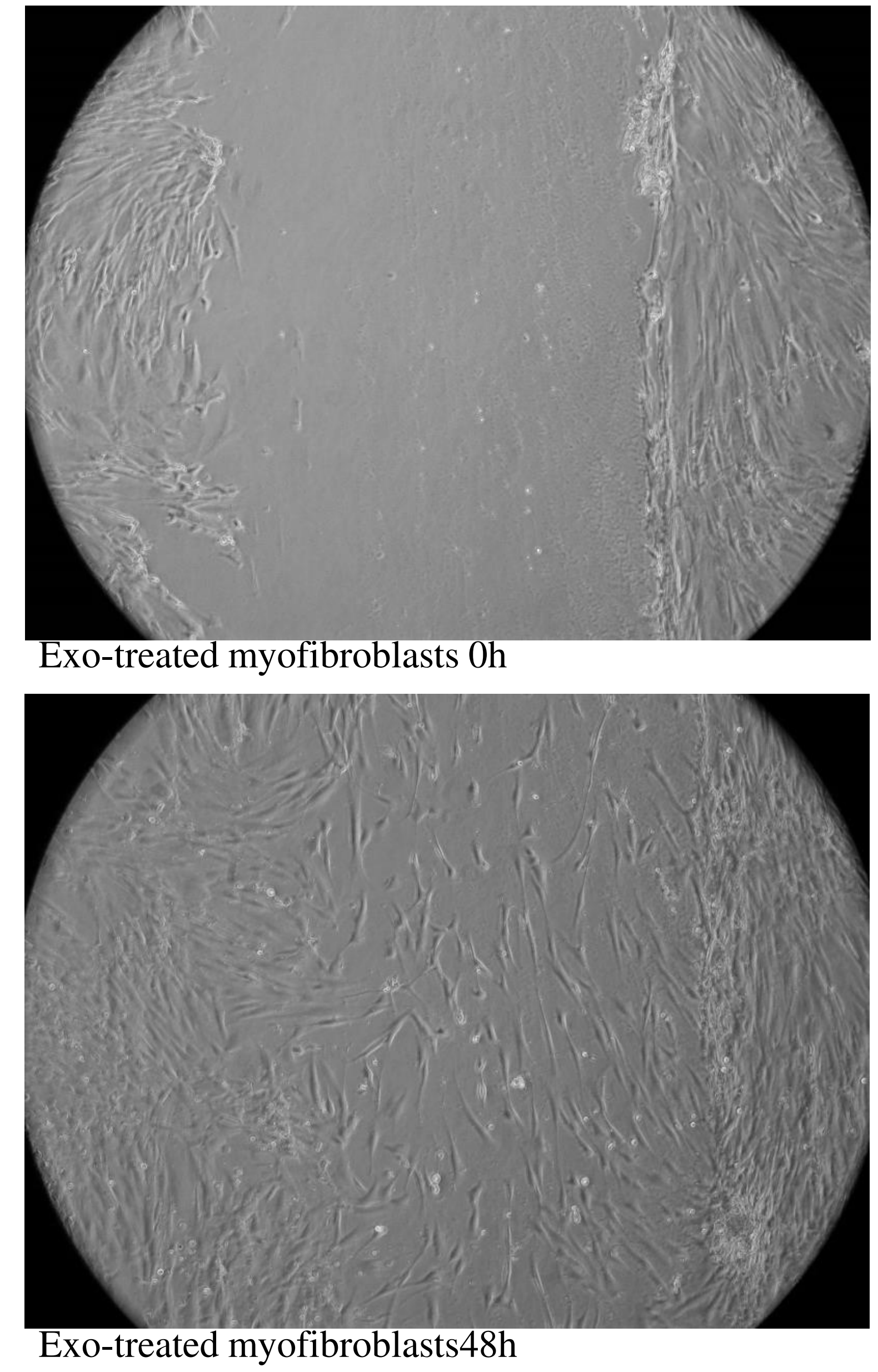

Average angle direction from origin [degree]

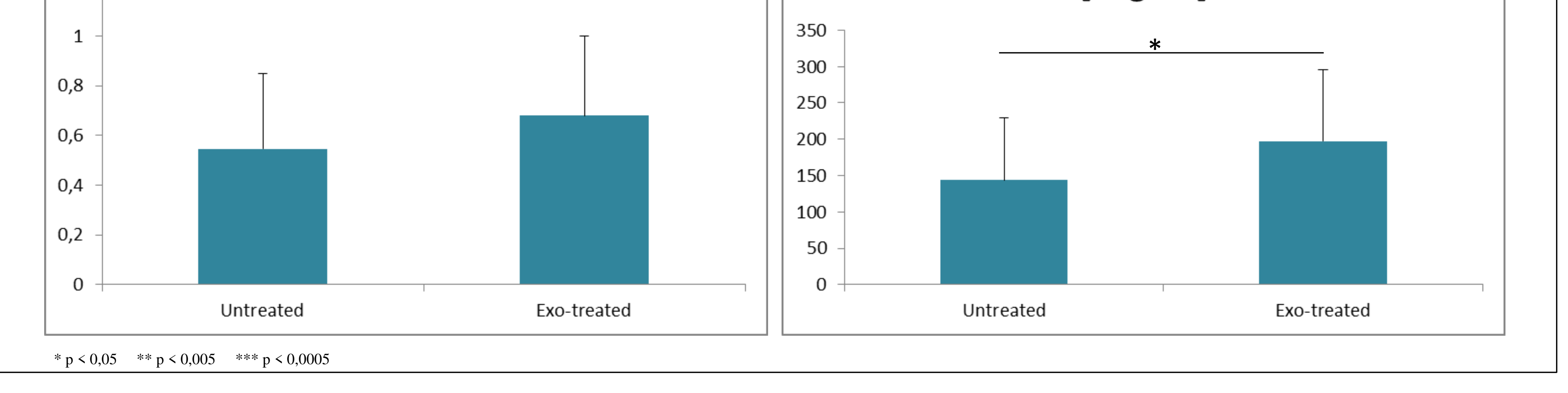

Melanoma-derived exosomes enhance SMA expression

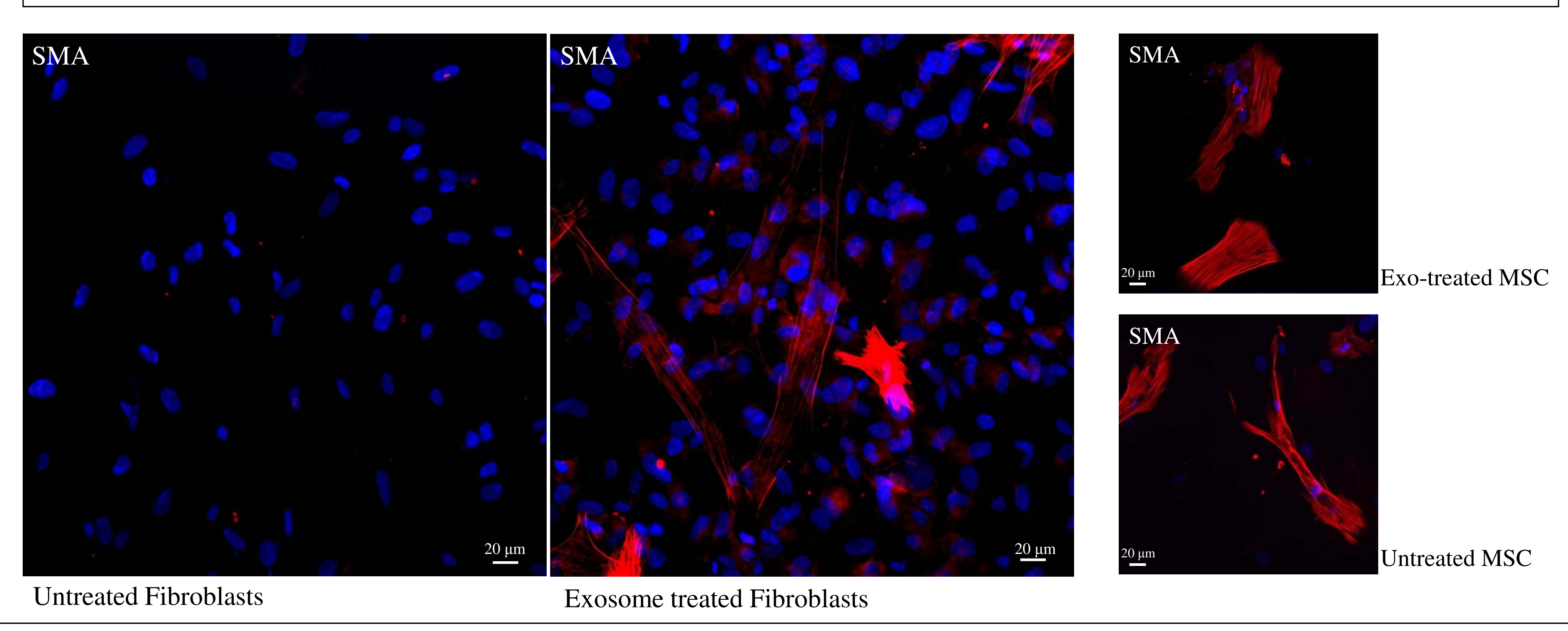

Melanoma-derived exosomes did not influence spontaneous cell fusion rate

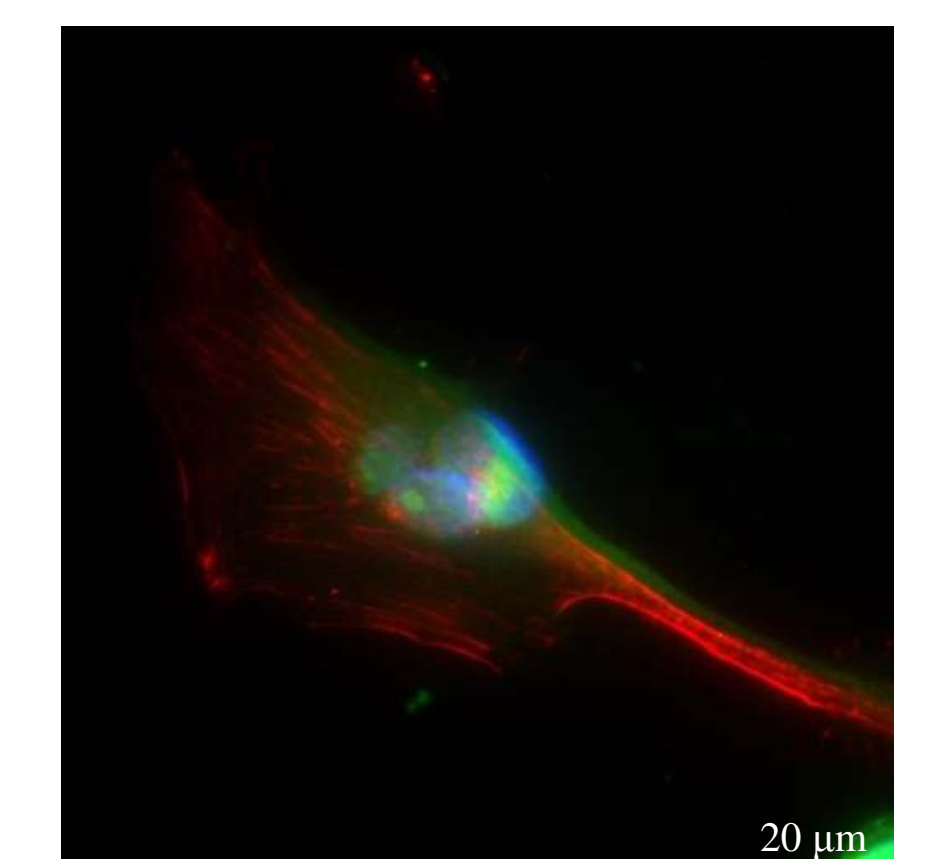

Previously we have shown that there is spontaneous cell fusion between fibroblasts and melanoma cells. ${ }^{(3)}$ Recently we also found double positive hybrid cells in melanoma-AD-MSC cocultures. However, in our experiments exosomes did not have effect on fusion rate.

Double positive, multinucleated MSC-melanoma hybrid from SMA Alexa-647-stained MSC and UACC-GFP melanoma parental cells.

\section{SUMMARY}

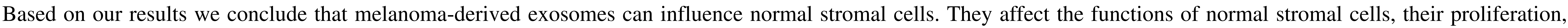

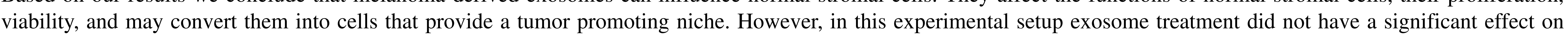

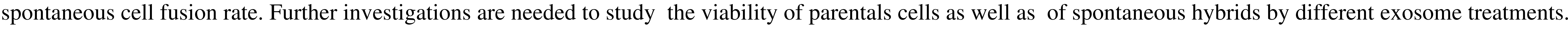

